\title{
Erratum to: Reduced AMP-activated protein kinase activity in mouse skeletal muscle does not exacerbate the development of insulin resistance with obesity
}

\section{S. Beck Jørgensen • H. M. O'Neill • K. Hewitt •}

B. E. Kemp • G. R. Steinberg

Published online: 18 November 2009

(C) Springer-Verlag 2009

\section{Erratum to: Diabetologia}

\section{DOI 10.1007/s00125-009-1483-8}

Unfortunately, the blots in Fig. $1 \mathrm{~b}$ and $6 \mathrm{~b}$ were mislabelled, as was the $y$-axis of Fig. 6a. The corrected figures are reproduced here.

Fig. 1b
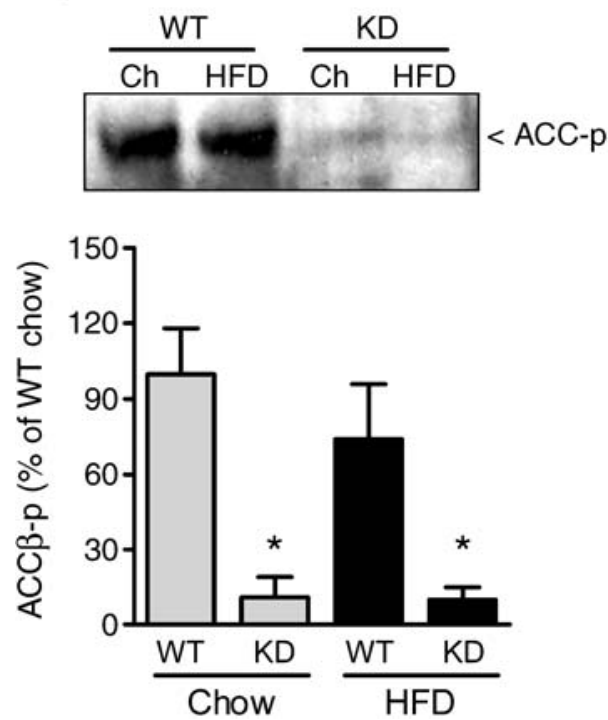

The online version of the original article can be found at http://dx.doi. org/10.1007/s00125-009-1483-8.

S. B. Jørgensen • H. M. O’Neill • K. Hewitt • B. E. Kemp •

G. R. Steinberg

St Vincent's Institute of Medical Research

and Department of Medicine, University of Melbourne,

Fitzroy, VIC, Australia

\section{S. B. Jørgensen $(\triangle)$}

Molecular Physiology Group, Section of Human Physiology,

Department of Exercise and Sport Sciences,

University of Copenhagen,

13-Universitetsparken,

2100 Copenhagen, Denmark

e-mail: sbjorgensen@ifi.ku.dk
Fig. 6a

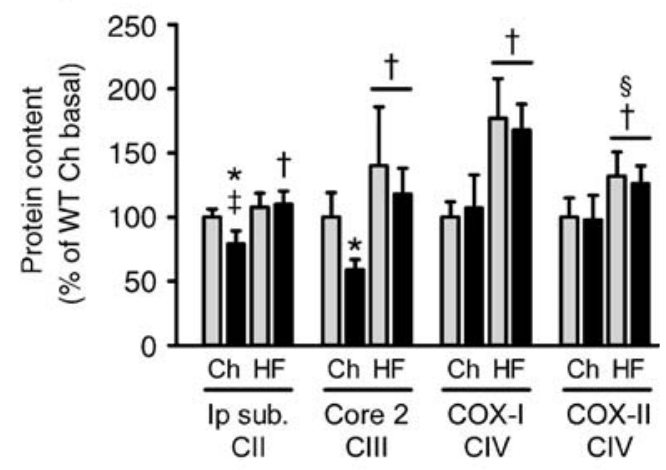

b

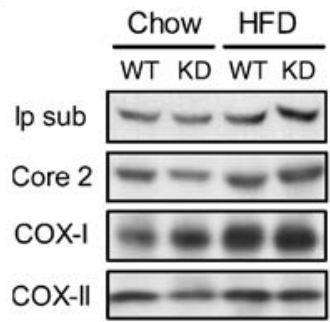

G. R. Steinberg

Department of Medicine, McMaster University,

Hamilton, ON, Canada 